\title{
Raising lingual flaps increases the risk of nerve damage
}

\section{Lingual nerve damage during lower third molar removal: a comparison of two surgical methods. Robinson PP, Smith K G. BrDent J: 1996; 180: 456-461}

Objective To determine whether avoiding the raising of a lingual flap reduces the incidence of lingual nerve disturbance and if this reduces the incidence of permanent nerve disturbance.

Design A randomised controlled trial in a UK dental school.

Intervention 378 patients had lower third molar removals carried out under local or general anaesthetic where a lingual flap was raised and 393 had lower third molars removed with no lingual flap. Operations were performed by several different grades of operator (from junior house office to consultant grade). There were no differences between the two groups in terms of grade of operator or type of anaesthetic. There were differences between the level of eruption, impaction and degree of difficulty between the groups - the effect of this is discussed in the text.

Outcome measures Patients' subjective assessment of altered sensation was assessed at one week. Patients reporting altered sensation were tested using light touch pinprick pain and sensation threshold, and two-point discrimination. If there was no recovery at 3-4 months surgical exploration and repair was carried out.

Results There was a significant difference in the level of paraesthesia between the two groups with $6.9 \%$ of patients in the lingual flap (control) group having paraesthesia and $0.8 \%$ in the no flap (test) group. This difference means that the absolute risk reduction in $6.1 \%$. That is you are $6 \%$ less likely to have paraesthesia if a lingual flap is not raised.

\begin{tabular}{lllll}
\hline $\begin{array}{l}\text { Nerve } \\
\text { damage }\end{array}$ & $\begin{array}{l}\text { Lingual } \\
\text { flap } \\
\text { raised } \\
(n=378)\end{array}$ & $\begin{array}{l}\text { Lingual } \\
\text { flap not } \\
\text { not raised } \\
(n=393)\end{array}$ & $\begin{array}{l}\text { Odds ratio } \\
(95 \% \mathrm{CI})\end{array}$ & $\begin{array}{l}\text { NNT } \\
(95 \% \mathrm{CI})\end{array}$ \\
$\begin{array}{l}\text { Temporary } \\
\text { lingual }\end{array}$ & $26(6.9 \%)$ & $3(0.8 \%)$ & $\begin{array}{l}9.01 \\
(3.4-23.7)\end{array}$ & $\begin{array}{l}17 \\
(11-29)\end{array}$ \\
$\begin{array}{l}\text { disturbance } \\
\begin{array}{l}\text { Permanent } \\
\text { lingual }\end{array}\end{array}$ & $3(0.8 \%)$ & $1(0.3 \%)$ & $\begin{array}{l}3.12 \\
(0.37-25.5)\end{array}$ & $\begin{array}{l}100 \\
\text { disturbance }\end{array}$ \\
\hline
\end{tabular}

(Odds ratios and Numbers needed to treat [NNT] calculated from data presented in paper).

Conclusions The authors concluded that the conventional UK method of lingual retraction using a Howarth's retractor is invalid and lingual retraction should be avoided.

Address P P Robinson, Department of Oral \& Maxillofacial Surgery, School of Clinical Dentistry, Claremont Crescent, Sheffield S10 2TA, UK

\section{Commentary}

This paper presents outcomes of a consecutive series of operations randomised into two groups. In one group a lingual flap was raised as is the custom in the United Kingdom, and a second in which no flap was used. The two groups were comparable for experience of she surgeon, type of anaesthesia and teeth requiring sectioning. An apparent mismatch of the groups as to degree and position of impaction was eliminated by exclusion of 124 procedures not involving bone removal. The process by which this was accomplished, operator feedback, raises some doubts on the general validity of the methods and the comparability of the groups. The two modified groups showed no differences in level of tooth eruption, type of impaction or degree of surgical difficulty. Exclusion of the 124 procedures also made time of operation comparable between groups although no mention is made of age being comparable between groups. In a previous study, which did not distinguish between lingual and inferior alveolar nerve identification, age was shown to be an important factor. ${ }^{1}$

The author's state that the data clearly show that lingual flap retraction results in a higher incidence of temporary lingual nerve disturbance but no increase en the incidence of permanent lingual nerve damage. Validity issues include questionable blindness of the randomisation and appropriateness of analysis of patients by the groups that they were originally assigned to. Real questions exist, based upon the feedback from operators described in the paper, as to clinician's input and knowledge of grouping, equal treatment based upon clinical judgements with modification made at the time of surgery and comparability of the initial groups.

Statistical significance must be distinguished from clinical importance. Based on the control event rate (CER) of $0.8 \%$ and experimental event rate (EER) of $6.9 \%$ for temporary numbness, the absolute risk reduction (ARR) is $6.1 \%$ and the number needed to treat (NNT) to see the benefit of avoiding the lingual flap would be 17 . The strength of the association between having a lingual flap performed and being numb temporarily clearly supports clinical importance even though the study does not demonstrate a similar association for permanent numbness. This study supports the current US practice of avoiding lingual retraction.

1 Osborn TP et al. A prospective study of complications related to mandibular third molar surgery. J Oral Maxillofac Surg 1985; 43: $761-769$.

\section{R. Bruce Donoff}

Dean and Head, Department of Oral Surgery, School of Dental Medicine, Harvard University, Boston USA 